\title{
Mast Cell Tryptase Induces Eosinophil Recruitment in the Pleural Cavity of Mice via Proteinase-Activated Receptor 2
}

\author{
Natália A. Matos, ${ }^{1}$ Josiane F. Silva, ${ }^{2}$ Tamires C. Matsui, ${ }^{1}$ Karine A. Damasceno, ${ }^{3}$ \\ Igor D. G. Duarte, ${ }^{1}$ Virginia S. Lemos, ${ }^{2}$ Geovanni D. Cassali, ${ }^{3}$ and André Klein ${ }^{1,4}$
}

\begin{abstract}
Proteinase-activated receptor (PAR) 2 has been implicated in eosinophil migration. Mast cell (MC) tryptase has been similarly implicated in allergic diseases through the activation of PAR2 , but the role of this receptor in MC tryptase-induced inflammation is not well elucidated. This study aims to investigate the ability of MC tryptase or PAR-2 activating peptide $\left(\mathrm{SLIGRL}-\mathrm{NH}_{2}\right)$ to induce eosinophil recruitment to the pleural cavity of mice. Mast cell tryptase-injected mice were pretreated with PAR-2 antagonist ENMD-1068. Mice injected with SLIGRL-NH $\mathrm{N}_{2}$ were pretreated with mast cell tryptase inhibitor APC 366, and eosinophil migration into the pleural cavity and PAR-2 expression was analyzed after 24 or $48 \mathrm{~h}$. SLIGRL-NH $\mathrm{N}_{2}$-induced eosinophil recruitment was inhibited by APC 366, and MC tryptase-induced eosinophil recruitment was abolished by ENMD1068. MC tryptase induced PAR-2 expression on pleural eosinophils. Our results demonstrate a key role for PAR-2 in mediating eosinophil recruitment in MC tryptase-induced pleurisy in mice. The ability of MC tryptase to inducing PAR-2 expression on eosinophils corroborates the relevance of MC tryptase and PAR-2 on modulating eosinophil migration.
\end{abstract}

KEY WORDS: eosinophils; eosinophil migration; mast cell tryptase; PAR-2; pleurisy.

\section{INTRODUCTION}

Eosinophils appear to play an important role in the pathogenesis of allergic diseases. They are typically tissuedwelling cells, and in allergic disorders, increased numbers of activated eosinophils are observed in the submucosa and mucosa of affected tissues [1]. These cells are considered the effectors of allergic and $\mathrm{MC} / \mathrm{IgE}-$ mediated reactions, and they are recruited from blood vessels into the allergy-

\footnotetext{
${ }^{1}$ Department of Pharmacology, Universidade Federal de Minas Gerais, Belo Horizonte, Brazil

${ }^{2}$ Department of Physiology and Biophysics, Universidade Federal de Minas Gerais, Belo Horizonte, Brazil

${ }^{3}$ Department of General Pathology, Universidade Federal de Minas Gerais, Belo Horizonte, Brazil

${ }^{4}$ To whom correspondence should be addressed at Departamento de Farmacologia, Instituto de Ciências Biológicas, Universidade Federal de Minas Gerais, Av. Antônio Carlos, 6627 Pampulha, 31270-901 Belo Horizonte, MG, Brazil. E-mail: klein@ufmg.br
}

inflamed tissue by the local production of eotaxin-1/CCL11, leukotriene (LT) $\mathrm{B}_{4}$, and IL-5 [1-4], which are produced by airway epithelial cells, macrophages, eosinophils, and mast cells [5-7]. Once at the tissue, eosinophils are a crucial source of cationic proteins, lipid mediators, oxygen-derived radicals, cytokines, and chemokines, which play an important role in the pathogenesis and severity of allergic diseases $[1,8]$. Thus, understanding the mechanisms underlying eosinophil recruitment in vivo may aid the development of novel strategies for the treatment of allergic diseases.

Mast cell (MC) tryptase is a neutral protease that is stored and released into the environment from MC secretory granules. MC tryptase plays an important role in airway remodeling, contributes to the pathogenesis of allergic diseases [9-12], and has been implicated in several hallmarks of inflammation and allergic diseases, including plasma exudation [13], neutrophil and eosinophil infiltration [14], cytokine release, expression of adhesion molecules [15], and contraction of smooth muscle bronchi [16]. Although the contribution of $\mathrm{MC}$ tryptase to the modulation 
of MC-mediated acute allergy has been demonstrated, its role in the modulation of eosinophil migration is not fully understood.

Mast cell tryptase shares with other serine proteases the ability to selectively activate G-protein-coupled proteinase-activated receptors (PARs) through the proteolytic cleavage of a specific site on the N-terminus of the receptor. This cleavage reveals the tethered ligand that binds to and activates the receptor [17]. PARs are a family of four receptors namely PAR 1 to 4 [17], whose activation has been implicated in the regulation of inflammation, including vascular endothelial cell activity, leukocyte recruitment [18-20], and cytokine release [21, 22]. Of particular interest, PAR-2 is the receptor for trypsin and MC tryptase $[23,24]$ and has been implicated in allergic diseases [11], eosinophil activation [25] as well as eosinophil and neutrophil migration [26]. In this work, we investigated the role of PAR-2 on MC tryptase- or PAR-2 activating peptide-induced eosinophil recruitment in the pleural cavity of mice.

\section{MATERIALS AND METHODS}

\section{Animals}

Male BALB/c mice (18-25 g) were used throughout the experiment. The mice were housed in a temperaturecontrolled room with free access to food and water. Throughout the experiments, the mice were managed in accordance with the principles and guidelines for the care of laboratory animals, and all experimental procedures were subject to evaluation and were approved by the local Animal Ethics Committee (certificate number 193/2012).

\section{Drugs and Reagents}

Human lung MC tryptase was purchased from MP Biomedicals (Solon, OH, USA). Anti-PAR-2 Ab was obtained from Santa Cruz Biotechnology (Santa Cruz, CA, USA). PAR-2 antagonist ENMD-1068 was purchased from Enzo Life Sciences (San Diego, CA, USA). PAR-2-activating peptide SLIGRL-NH $\mathrm{N}_{2}$, PAR-2 peptide control LRGILS-NH 2 , and the selective inhibitor of MC tryptase APC 366 were purchased from Tocris Bioscience (Bristol, UK). ENMD 1068, SLIGRL-NH 2 , and the PAR2 inactive peptide control LRGILS- $\mathrm{NH}_{2}$ were dissolved in phosphate-buffered saline (PBS, pH 7.4), APC366 was diluted in $20 \% \mathrm{DMSO}$ and $80 \% \mathrm{PBS}$, and all samples were stored at $-20{ }^{\circ} \mathrm{C}$ until use. Control mice received vehicle only.

\section{Eosinophil Migration into the Pleural Cavity Induced by MC Tryptase}

Boiled MC tryptase $(300 \mathrm{ng} / 0.1 \mathrm{ml})$, MC tryptase (30-300 ng/0.1 ml), or vehicle (PBS/0.1 ml) was injected intrapleurally (i.pl.). Mice were sacrificed in a $\mathrm{CO}_{2}$ chamber at different times following the i.pl. injection (4, 24 , 48, or $72 \mathrm{~h}$ ). The cells present in the cavity were harvested by injecting $2 \mathrm{ml}$ of PBS, and total cell counts were performed in a modified Neubauer chamber using Turks stain. Differential cell counts were performed on cytospin preparations stained with May Grunwald using standard morphological criteria to identify cell types, as previously described [27]. The results were presented as the number of cells per cavity.

\section{Effects of PAR-2 Antagonist Pretreatment on Eosinophil Recruitment Induced by MC Tryptase}

To investigate the contribution of PAR-2 in MC tryptase-induced eosinophil recruitment, the PAR-2 antagonist ENMD 1068 (3 $\mu \mathrm{g})$ was administered i.pl. $15 \mathrm{~min}$ prior to the i.pl. injection of tryptase $(300 \mathrm{ng} / 0.1 \mathrm{ml})$. The number of infiltrating eosinophils was assessed after $24 \mathrm{~h}$.

\section{Effects of MC Tryptase Inhibitor APC 366 \\ on Eosinophil Recruitment Induced by PAR-2-Activating Peptide SLIGRL-NH}

To confirm the importance of MC tryptase in mediating eosinophil migration to the pleural cavity, mice were pretreated subcutaneously (s.c.) with the irreversible $\mathrm{MC}$ tryptase inhibitor APC $366(5 \mathrm{mg} / \mathrm{kg}) 1 \mathrm{~h}$ prior to i.pl. injection of PAR-2-activating peptide SLIGRL-NH $2(30 \mu \mathrm{g} /$ $0.1 \mathrm{ml})$ or PAR-2 peptide control LRGILS-NH $\mathrm{N}_{2}(30 \mu \mathrm{g} /$ $0.1 \mathrm{ml}$ ). The number of infiltrating eosinophils was assessed after $24 \mathrm{~h}$.

\section{Western Blot Analysis of Leukocyte PAR-2 Expression in MC Tryptase-Injected Mice}

To investigate the expression of PAR-2 in pleural fluid leukocytes, pleural fluid washes from MC tryptase-treated mice $(300 \mathrm{ng} / 0.1 \mathrm{ml})$ were obtained at 4, 8, 24, and $48 \mathrm{~h}$ after i.pl. injection of tryptase. Four animals were used for each time point. The fluid recovered from the animals in each group was pooled and centrifuged at $1,300 \times \mathrm{g}$. Lysis buffer $(0.3 \mathrm{ml}$; in millimoles per liter: $150 \mathrm{NaCl}, 50$ Tris- $\mathrm{HCl}, 5$ EDTA.2Na, and $1 \mathrm{MgCl} 2$ ) containing $1 \%$ Triton X-100 and $0.5 \%$ SDS plus a cocktail of protease inhibitors (SigmaFAST) was added to the cell pellets. The lysate was centrifuged at $8,000 \times g$ for $8 \mathrm{~min}$, and the protein 

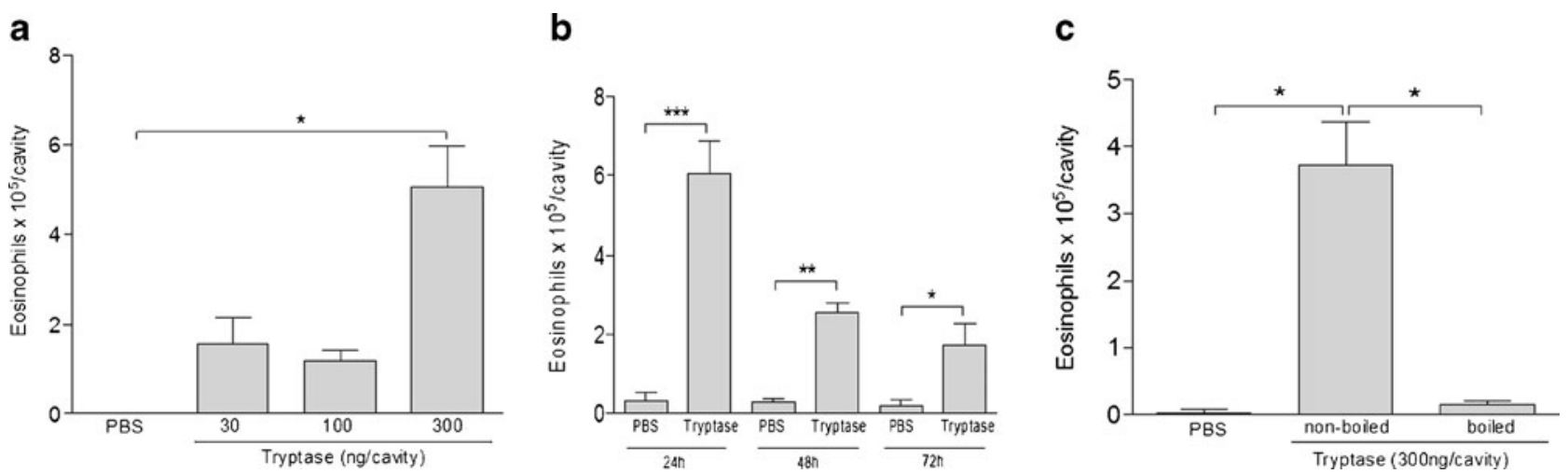

Fig. 1. Eosinophil recruitment induced by the injection of $\mathrm{MC}$ tryptase into the pleural cavity of mice. Mice were challenged by i.pl. administration of MC tryptase at the indicated doses (30-300 ng/cavity), and cells were harvested after $24 \mathrm{~h} .{ }^{*} P<0.001$ in comparison to respective control (a). In kinetic experiments, a dose of $300 \mathrm{ng}$ of tryptase was used, and cells were harvested at 24,48 , or $72 \mathrm{~h}$ after stimulation with tryptase, $* P<0.05, * * P<$ $0.01, * * * P<0.001$ in comparison to respective controls (b). Mice were challenged by i.pl. administration of boiled MC tryptase (300 ng), and cells were harvested $24 \mathrm{~h}$ after, ${ }^{*} P<0.001(\mathbf{c})$. The results are expressed as the mean $\pm \mathrm{SEM}$ of four to seven animals in each group.

concentration in the supernatant was determined spectrophotometrically by the Bradford method. Thirty micrograms of protein was separated using a denaturing SDS polyacrylamide gel $(10 \%)$ and transferred to a nitrocellulose membrane (Millipore). Blots were blocked with $3 \%$ bovine serum albumin (BSA) in TBS and $0.1 \%$ tween 20 at $4{ }^{\circ} \mathrm{C}$ overnight. The primary antibodies (Santa Cruz Biotechnology, Santa Cruz, CA) used were PAR-2 goat polyclonal IgG (1:1.000) and mouse monoclonal anti- $\beta$ actin (1:3.000). The secondary antibodies used were goat anti-mouse IgG-HRP (1:8.000) and rabbit anti-goat IgGHRP (1:8.000), both from Millipore. Immunocomplexes were detected using a chemiluminescent reaction (Luminata Western HRP Substrates-Millipore ${ }^{\circledR}$ ), followed by densitometric analyses with the ImageQuant software package. $\beta$-Actin content was used to normalize total PAR-2 protein content.

\section{Immunohistochemical Analysis of PAR-2 in Leukocytes of MC Tryptase-Injected Mice}

Pleural washes were obtained at 24 or $48 \mathrm{~h}$ after the i.pl. injection of MC tryptase $(300 \mathrm{ng} / 0.1 \mathrm{ml})$. The samples were centrifuged, and the resulting pellet was resuspended in PBS containing $3 \%$ BSA. Cytospins containing $5 \times 10^{4}-10^{5}$ cells were prepared. Slides were fixed in $70 \%$ alcohol until use. Slides were washed with PBS for 5 min and incubated in $10 \%$ hydrogen peroxide (30 vol.) and $90 \%$ methanol for 15 min twice to block endogenous peroxidase. Slides were then rinsed with PBS twice for 5 min each. Ultra Block V (Thermoscientific) was used to block endogenous biotin. Next, the slides were incubated with rabbit anti-murine PAR2 primary antibody (Santa Cruz Biotechnology, USA) at 1:100 for $1 \mathrm{~h}$ at $37^{\circ} \mathrm{C}$. A biotin-peroxidase system was used in the immunohistochemical procedure, with identification of the secondary antibody by the polymer (ADVANCE HRP-

Table 1. Total and Differential Cell Counts $\left(\times 10^{5}\right.$ Cells/Cavity $)$ in Response to the i.pl. Injection of MC Tryptase in Mice

\begin{tabular}{lllll}
\hline & & \multicolumn{3}{l}{ MC tryptase $(\mathrm{ng} / 0.1 \mathrm{ml} /$ cavity) } \\
\cline { 3 - 5 } & PBS & 30 & 100 & 300 \\
\hline Total & $11.6 \pm 1.7$ & $24.2 \pm 3.6$ & $17.4 \pm 3.4$ & $37.7 \pm 7.0^{*}$ \\
Eosinophils & $0.0 \pm 0.0$ & $1.5 \pm 0.2$ & $1.2 \pm 0.2$ & $5.0 \pm 0.9^{* *}$ \\
Mononuclear cells & $11.2 \pm 1.4$ & $22.7 \pm 3.6$ & $16.2 \pm 3.1$ & $32.4 \pm 6.2^{*}$ \\
Neutrophils & $0.4 \pm 0.2$ & $0.04 \pm 0.04$ & $0.05 \pm 0.05$ & $0.3 \pm 0.1$ \\
\hline
\end{tabular}

MC tryptase (30-300 ng/0.1 ml) was administered i.pl., and leukocyte migration was assessed $24 \mathrm{~h}$ after injection. The results are expressed as the mean $\pm \mathrm{SEM}$ of five to seven mice in each group

${ }^{*} P<0.01$ when compared with the PBS-treated group; $* * P<0.001$ when compared with the PBS-treated group 
Table 2. Total and Differential Cell Counts $\left(\times 10^{5}\right.$ Cells/Cavity) in Response to the i.pl. Injection of MC Tryptase in Mice

\begin{tabular}{lll}
\hline & PBS & Tryptase (300 ng/cavity) \\
\hline Total & $23.4 \pm 2.8$ & $53.3 \pm 5.8^{* * *}$ \\
Eosinophils & $0.3 \pm 0.1$ & $1.5 \pm 0.2^{* * * *}$ \\
Mononuclear cells & $23.0 \pm 0.3$ & $43.6 \pm 4.2^{* *}$ \\
Neutrophils & $0.1 \pm 0.1$ & $8.2 \pm 2.1^{*}$ \\
\hline
\end{tabular}

MC tryptase $(300 \mathrm{ng} / 0.1 \mathrm{ml})$ was administered i.pl., and leukocyte migration was assessed $4 \mathrm{~h}$ after injection. The results are expressed as the mean \pm SEM of five mice in each group

${ }^{*} P=0.02$ when compared with PBS-treated group; ${ }^{*} P=0.007$ when compared with PBS-treated group; $* * * P=0.0059$ when compared with PBStreated group; $* * * P=0.0033$ when compared with PBS-treated group

ready to use-DakoCytomation). Diaminobenzidine was used as a chromogen, and cells were counterstained with Mayer's hematoxylin, dehydrated, and mounted (with balm). Negative controls were obtained by the omission of primary antibodies.

\section{Statistical Analysis}

The results of the eosinophil recruitment assays are presented as the mean \pm standard error mean (SEM), and they were analyzed using the software SigmaStat ${ }^{\circledR} 3.5$ (San Diego, CA, USA). Comparisons between groups were performed using Student's $t$ test or one-way ANOVA, and differences between groups were assessed using the Newman-Keuls post-test. $P<0.05$ was considered significant. For Western blot analysis or in boiled MC tryptase experiments, statistical analyses were performed using Student's $t$ test.

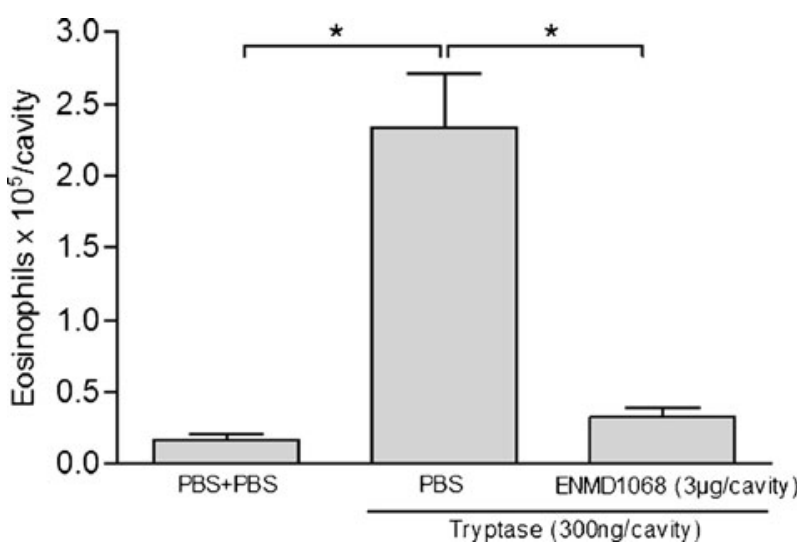

Fig. 2. Effects of PAR-2 antagonist on eosinophil recruitment in response to MC tryptase injection into the pleural cavity of mice. Mice were pretreated with i.pl. injection of ENMD-1068 (3 $\mu \mathrm{g} /$ cavity) or PBS 15 min before i.pl. injection of MC tryptase ( $300 \mathrm{ng} /$ cavity). The number of infiltrating eosinophils was assessed after $24 \mathrm{~h}$. The results are expressed as the mean \pm SEM of six to eight animals in each group, $* P<0.001$ in comparison to respective controls.

\section{RESULTS}

\section{Mast Cell Tryptase-Induced Eosinophil Recruitment in the Pleural Cavity of Mice}

Initial experiments were designed to test the ability of MC tryptase to induce eosinophil recruitment into the pleural cavity of mice. The i.pl. injection of MC tryptase $(300 \mathrm{ng} / 0.1 \mathrm{ml})$ induced the recruitment of eosinophils at 4 and $24 \mathrm{~h}$ (Fig. 1a, Tables 1 and 2). Significant levels of neutrophils and mononuclear cells are also present $4 \mathrm{~h}$ after MC tryptase administration (Table 2); however, neutrophils are not detectable at $24 \mathrm{~h}$ (Table 1). Eosinophil recruitment induced by $\mathrm{MC}$ tryptase peaked $24 \mathrm{~h}$ after i.pl. injection and dropped by 48 and $72 \mathrm{~h}$ later (Fig. 1b). MC tryptase-induced eosinophil recruitment was abolished after tryptase boiling (Fig. 1c). PAR-2 plays an important role in the MC tryptase-induced recruitment of eosinophils.

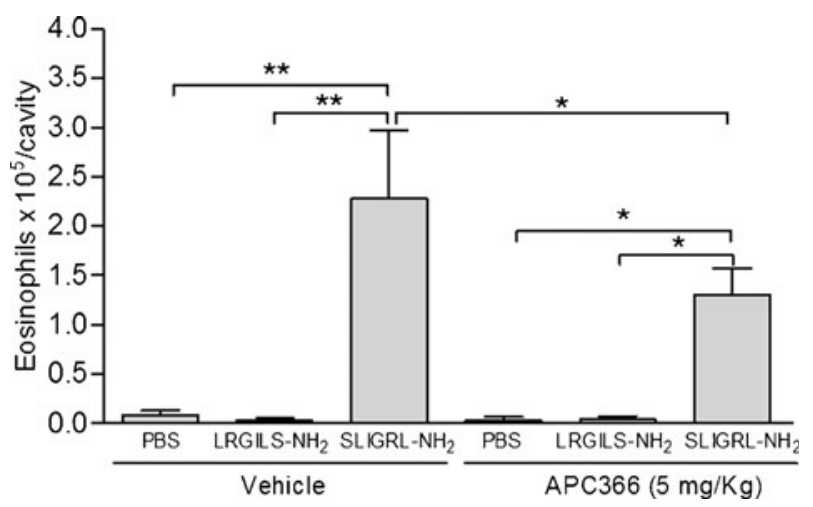

Fig. 3. Effects of MC tryptase inhibitor APC 366 on the eosinophil recruitment induced by PAR-2 activating peptide. Mice were pretreated s.c. with the MC tryptase inhibitor APC $366(5 \mathrm{mg} / \mathrm{kg} / 0.1 \mathrm{ml})$ or vehicle $1 \mathrm{~h}$ prior to the i.pl. injection of vehicle (DMSO $20 \%+$ PBS $80 \% / 0.1 \mathrm{ml})$, LRGILS-NH2 $(30 \mu \mathrm{g} / 0.1 \mathrm{ml})$, or SLIGRL-NH2 $(30 \mu \mathrm{g} /$ $0.1 \mathrm{ml})$. Cells were harvested $24 \mathrm{~h}$ after the i.pl. injection. The results are expressed as the mean \pm SEM of four to five animals in each group. ${ }^{*} P<0.05 ; * * P<0.001$ in comparison to respective controls. 
Because injection of MC tryptase into the pleural cavity was effective at inducing eosinophil recruitment and MC tryptase activates PAR-2, we examined whether the blockade of PAR-2 would interfere with the recruitment of eosinophils. As seen in Fig. 2, pretreatment with the PAR-2 antagonist ENMD 1068 abolished the recruitment of eosinophils induced by tryptase ( $87 \%$ of inhibition).

PAR-2 activating peptide induces eosinophil recruitment, and inhibition of mast cell tryptase attenuates this effect. Given that PAR-2 is required for MC tryptaseinduced eosinophil recruitment, we designed experiments to test the contribution of PAR-2 activating peptide on eosinophil influx. PAR-2 activating peptide SLIGRL- $\mathrm{NH}_{2}$, but not PAR-2 inactive peptide control LRGILS-NH $\mathrm{N}_{2}$, induced eosinophil recruitment in the pleural cavity of mice. We additionally tested the contribution of MC tryptase activity in mice treated with PAR-2 activating peptide. MC tryptase inhibitor APC 3866 treatment reduced (43\%) the eosinophil influx induced by PAR-2 activating peptide (Fig. 3).

PAR-2 is expressed in inflammatory cells in the pleural cavity after MC tryptase injection. In support of an important role for PAR-2 in the recruitment of eosinophils, PAR-2 was detected on cells harvested from the pleural cavity after MC tryptase challenge. PAR-2 was significantly increased $24 \mathrm{~h}$ after MC tryptase challenged when compared to PBS-injected mice, with levels dropping thereafter (Fig. 4). Cytospin preparations obtained from pleural washes were stained with May Grunwald or immunostained with anti-PAR-2 antibody to examine surface expression. There are no eosinophils in pleural cavity 24 h after PBS administration (Fig. 5 a). Eosinophils and mononuclear cells, but not neutrophils, were detected on cytospin preparation $24 \mathrm{~h}$ after i.pl. MC tryptase (Fig. 5b), and PAR-2 was detected on eosinophils and mononuclear cells 24 or $48 \mathrm{~h}$ after MC tryptase injection (Fig. 5c-e). PAR-2 was not detected in leukocytes obtained from PBS-injected mice (data not shown).

\section{DISCUSSION}

There is much evidence suggesting an important role for eosinophils in the pathophysiology of allergic diseases, such as asthma and atopic dermatitis. It is thus hypothesized that drugs which block eosinophil recruitment and/or activation may become important new therapeutic strategies for the treatment of these allergic diseases, and a detailed understanding of the pathways and, specifically, of the chemoattractant molecules necessary for the migration and activation of eosinophils will be important in the development of such strategies [1]. PARs, with the exception of PAR-3, can be pharmacologically modulated by the use of short synthetic peptides derived from the tethered ligand, which cleaves a sequence on the $\mathrm{N}$-terminus for activation or at a non-receptor activating site. Thus, PAR-activating peptides and PAR antagonists have been useful tools in the study of PARs in the physiological development of diseases; accordingly, they have emerged as promising potential treatments for inflammatory diseases [28]. In this study, we investigated the ability of the endogenous PAR-2 agonist $\mathrm{MC}$ tryptase to induce eosinophil recruitment in the pleural cavity of mice.

Our initial experiments were designed to investigate whether MC tryptase induces eosinophil recruitment in the pleural cavity of mice. MC tryptase activates PAR-2 [11, $29,30]$ and induces several hallmarks of inflammation, including plasma exudation, neutrophil and eosinophil infiltration, and release of eosinophil peroxidase [13-15, 31]. Furthermore, in clinical trials the irreversible MC tryptase inhibitor APC 366 has been effective to reduce antigen-induced late asthmatic response in atopic asthmatics, supporting a role for MC tryptase in the development of asthma [32]. In the present experiments, MC

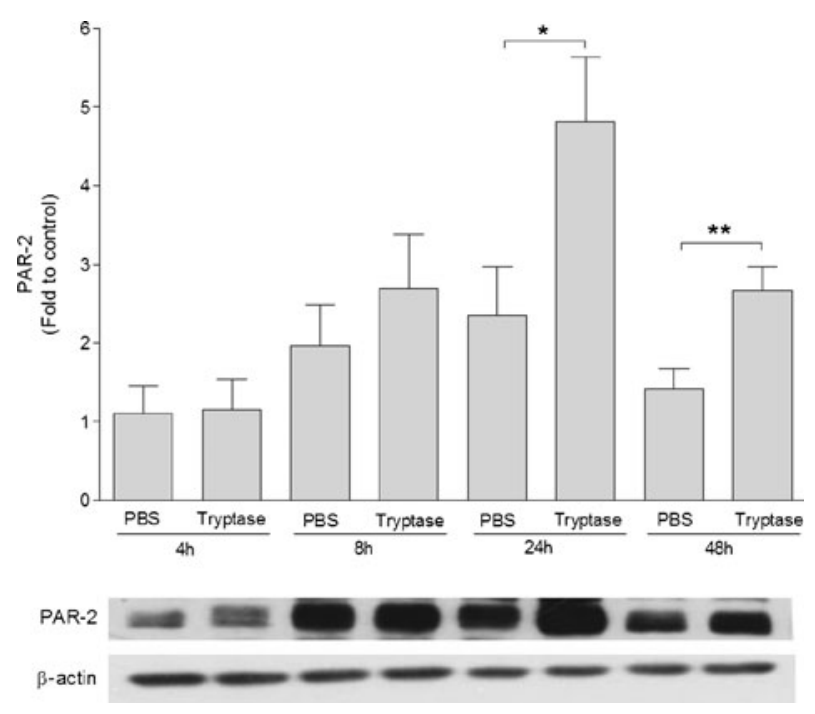

Fig. 4. Western blot analysis of PAR-2 protein expression following injection with MC tryptase. Mice were injected i.pl. with MC tryptase (300 ng/cavity), and the pleural cavity was washed at different times after challenge (four animals for each time point). The cells were centrifuged and pooled, and protein expression was determined by Western blot. This gel is representative of four experiments with similar outcomes. The results were normalized by respective PBS-injected group. Statistical analyses were performed using Student's $t$ test, where $* P=0.0486$ and $* * P=0.017$. 


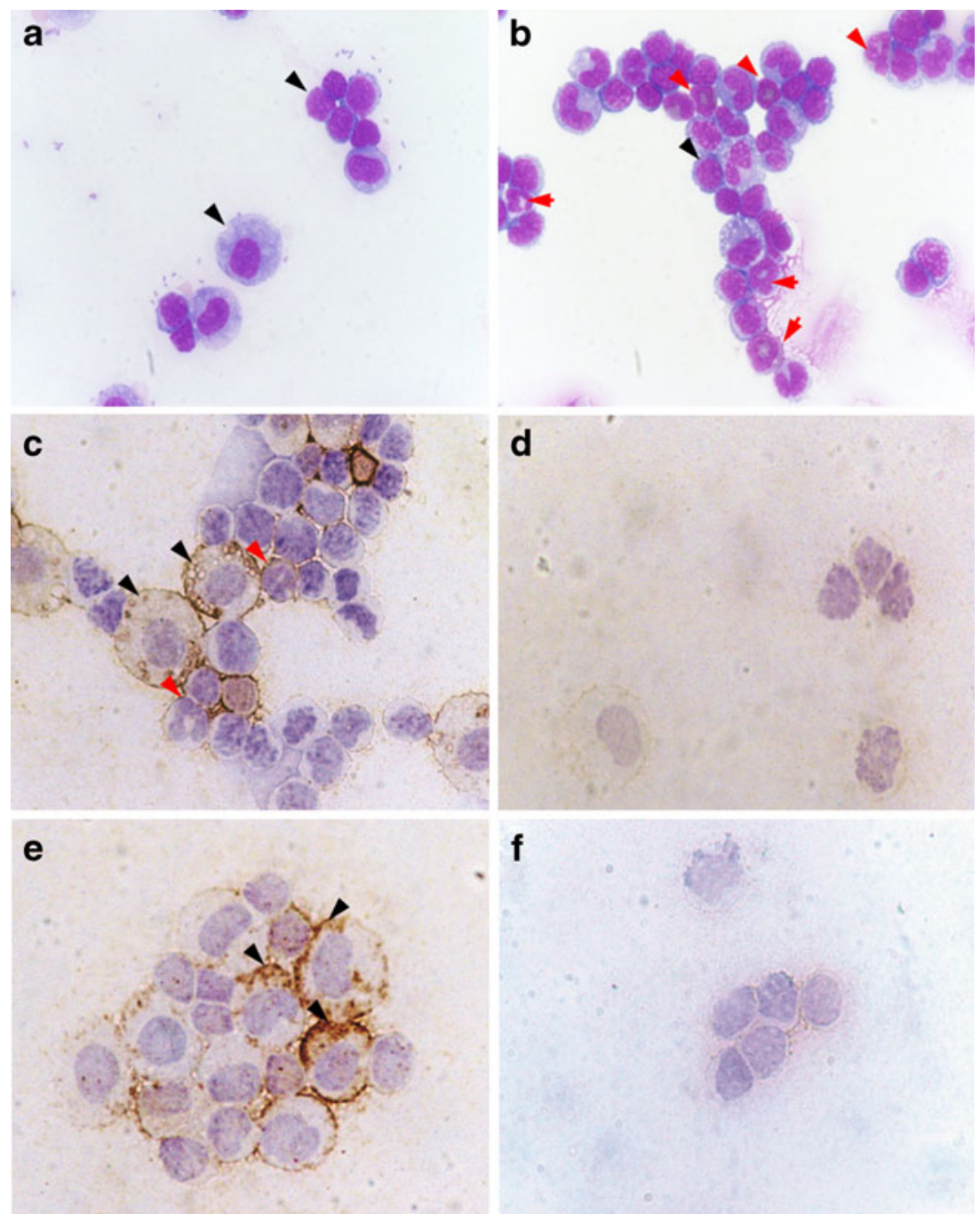

Fig. 5. PAR-2 localization on pleural leukocytes following MC tryptase injection. Mice were challenged by i.pl. administration of PBS (a) or MC tryptase (300 ng/cavity, b) and $24 \mathrm{~h}$ after cells were harvested and cytospin preparation was stained with May Grunwald (eosinophils, red arrows and mononuclear cells, black arrows). Cells were harvested after $24(\mathbf{c}, \mathbf{d})$ or $48 \mathrm{~h}(\mathbf{e}, \mathbf{f})$, and pleural cavity cells were immunostained for PAR-2 expression with a rabbit anti-murine PAR-2 antibody (c, e) or without primary antibody (d, f). PAR-2 was localized to eosinophils (red arrows) and mononuclear cells (black arrows). The data presented are representative of three experiments with similar results.

tryptase induces eosinophil recruitment into the pleural cavity of mice peaked $24 \mathrm{~h}$ after administration through PAR-2 activation, and importantly, this effect was dependent of MC tryptase proteolytic activity.

In recent years, PAR-2 has been studied focusing on understanding their role in mechanisms of leukocyte recruitment or activation [33, 34]. PAR-2 agonists have been shown to induce the production of chemokines and the expression of endothelial adhesion molecules E, P-selectins, vascular cell adhesion molecule 1 , and intercellular adhesion molecule-1 [35, 36]. However, the role of PAR-2 in eosinophil recruitment is still controversial. In a model of ovalbumin-induced airway inflammation, Schmidlin et al. showed that eosinophil infiltration in the lungs of mice was inhibited in mice lacking PAR-2, and conversely, eosinophil migration was increased in mice overexpressing PAR-2 [26]. In contrast, De Campo and Henry demonstrated that intranasal administration of PAR-2-activating peptide inhibited eosinophil infiltration after allergen challenge when compared to peptide-control-treated mice [37]. Our 
results are in agreement with a proinflammatory effect for PAR-2 and support a role for MC tryptase in mediating eosinophil migration via PAR-2 signaling.

Once the recruitment of eosinophils by MC tryptase was inhibited by the blockade of PAR-2, we examined the contribution of MC tryptase activity and PAR-2 to eosinophil recruitment induced by PAR-2 activating peptide. PAR2 activating peptide SLIGRL-NH 2 , but not PAR-2 inactive peptide control LRGILS-NH ${ }_{2}$, induced eosinophil migration into the pleural cavity. Because SLIGRL- $\mathrm{NH}_{2}$ is a selective PAR-2 agonist, and SLIGRL-NH $\mathrm{N}_{2}$-induced eosinophil migration was partially inhibited by the irreversible MC tryptase inhibitor APC 366 treatment, these results confirm the importance of PAR-2 activation and MC tryptase activity in mediating eosinophil recruitment and pleurisy. In agreement for a role for MC tryptase mediating inflammation through PAR-2 signalling, PAR-activating peptides promoted MC degranulation [38], and interestingly, the blockade of PAR-2 reduced MC degranulation in a rat model of arthritis and also inhibited MC tryptase-induced paw edema in rats [39].

PAR-2 is expressed in different cell types, including airway smooth muscle cells, mast cells, eosinophils, and airway cells in response to antigen or trypsin $[11,16,35,40]$; however, MC tryptase-induced PAR-2 expression on eosinophils has not been still demonstrated. In support of an important role of PAR-2 on mediating MC tryptase-induced eosinophil recruitment, significant PAR-2 protein has been detected in pleural washes after MC tryptase challenge. Moreover, PAR-2 immunoreactivity was detected in pleural cavity cells in eosinophils and macrophages. There are conflicting data concerning the basal PAR-2 expression on eosinophils. PAR-2 expression on eosinophils may be highly increased in the nasal mucosa of patients with seasonal allergic rhinitis in comparison to non-allergic patients [40]; however, in another study there was no difference in PAR-2 expression between normal and asthmatic purified human eosinophils. In the present study, we provide evidences for the first time for a role for MC tryptase mediating eosinophil recruitment through PAR-2 activation. Furthermore, the ability of MC tryptase to inducing eosinophil recruitment through PAR-2 activation has not been yet demonstrated, and there are no other studies concerning the ability of PAR-2 antagonist to inhibit the eosinophil recruitment into pleural cavity.

In conclusion, this work demonstrates a key role for PAR-2 in mediating eosinophil recruitment in MC tryptaseinduced pleurisy in mice. Other studies have previously shown the ability of PAR agonists to modulate leukocyte activation in response to a range of different stimuli; however, there are yet controversial data regarding the role of PAR-2 and its endogenous agonist MC tryptase mediating this process. The ability of MC tryptase to inducing PAR-2 expression on eosinophils corroborates the relevance of this protease and PAR-2 on modulating eosinophil migration. Given that PAR-2 blockade may reduce the migration of eosinophils induced by MC tryptase and once this protease is found in sites of acute allergic inflammation, a PAR-2-based therapy may be a relevant principle in the treatment of allergic diseases.

\section{ACKNOWLEDGMENTS}

This work was supported by Conselho Nacional de Pesquisa e Desenvolvimento (CNPq/Brazil), Fundação de Amparo à Pesquisa de Minas Gerais (FAPEMIG/ Brazil) and CAPES/Brazil.

Conflict of Interest. The authors declare no financial interests.

\section{REFERENCES}

1. Rothenberg, M.E., and S.P. Hogan. 2006. The eosinophil. Annu Rev Immunol 24: 147-174.

2. Pope, S.M., N. Zimmermann, K.F. Stringer, M.L. Karow, and M.E. Rothenberg. 2005. The eotaxin chemokines and CCR3 are fundamental regulators of allergen-induced pulmonary eosinophilia. J Immunol 175: 5341-5350.

3. Faccioli, L.H., S. Nourshargh, R. Moqbel, F.M. Williams, R. Sehmi, A.B. Kay, and T.J. Williams. 1991. The accumulation of ${ }^{111}$ In-eosinophils induced by inflammatory mediators, in vivo. Immunology 73(2): 222-227.

4. Faccioli, L.H., V.F. Mokwa, C.L. Silva, G.M. Rocha, J.I. Araujo, M.A. Nahori, and B.B. Vargaftig. 1996. IL-5 drives eosinophils from bone marrow to blood and tissues in a guinea-pig model of visceral larva migrans syndrome. Mediators Inflamm 5(1): 24-31.

5. Cook, E.B., J.L. Stahl, C.M. Lilly, K.J. Haley, H. Sanchez, A.D. Luster, F.M. Graziano, and M.E. Rothenberg. 1998. Epithelial cells are a major cellular source of the chemokine eotaxin in the guinea pig lung. Allergy Asthma Proc 19: 15-22.

6. Hirata, K., K. Maghni, P. Borgeat, and P. Sirois. 1990. Guinea pig alveolar eosinophils and macrophages produce leukotriene B4 but no peptido-leukotriene. J Immunol 144: 1880-1885.

7. Martin, T.R., L.C. Altman, R.K. Albert, and W.R. Henderson. 1984. Leukotriene B4 production by the human alveolar macrophage: a potential mechanism for amplifying inflammation in the lung. Am Rev Respir Dis 129: 106-111.

8. Hogan, S.P. 2007. Recent advances in eosinophil biology. Int Arch Allergy Immunol 143(Suppl 1): 3-14.

9. Blank, U., and J. Rivera. 2004. The ins and outs of IgE-dependent mast-cell exocytosis. Trends Immunol 25: 266-273.

10. Pejler, G., M. Åbrink, M. Ringvall, and S. Wernersson. 2007. Mast cell proteases. Adv Immunol 95: 167-255. 
11. Pejler, G., E. Ronnberg, I. Waern, and S. Wernersson. 2010. Mast cell proteases: multifaceted regulators of inflammatory disease. Blood. doi:10.1182/blood-2010-01-257287.

12. Wedemeyer, J., and S.J. Galli. 2000. Mast cells and basophils in acquired immunity. Br Med Bull 56: 936-955.

13. He, S., and A.F. Walls. 1997. Human mast cell tryptase: a stimulus of microvascular leakage and mast cell activation. Eur $J$ Pharmacol 328: 89-97.

14. He, S., Q. Peng, and A.F. Walls. 1997. Potent induction of a neutrophil and eosinophil-rich infiltrate in vivo by human mast cell tryptase: selective enhancement of eosinophil recruitment by histamine. J Immunol 159: 6216-6225.

15. Compton, S.J., J.A. Cairns, S.T. Holgate, and A.F. Walls. 1998. The role of mast cell tryptase in regulating endothelial cell proliferation, cytokine release, and adhesion molecule expression: tryptase induces expression of mRNA for IL-1 and IL- 8 and stimulates the selective release of IL-8 from human umbilical vein endothelial cells. $J$ Immunol 161: 1939-1946.

16. Schmidlin, F., S. Amadesi, R. Vidil, M. Trevisani, N. Martinet, G. Caughey, et al. 2001. Expression and function of proteinaseactivated receptor 2 in human bronchial smooth muscle. Am J Respir Crit Care Med 164: 1276-1281.

17. Hollenberg, M.D., and S.J. Compton. 2002. International Union of Pharmacology. XXVIII. Proteinase-activated receptors. Pharmacol Rev 54: 203-217.

18. Vergnolle, N., C.K. Derian, M.R. D’Andrea, M. Steinhoff, and P. Andrade-Gordon. 2002. Characterization of thrombin-induced leukocyte rolling and adherence: a potential proinflammatory role for proteinase-activated receptor-4. J Immunol 169: 1467-1473.

19. Braga, A.D., J.P. Miranda, G.M. Ferreira, R.P. Bilheiro, I.D. Duarte, J.N. Francischi, and A. Klein. 2010. Blockade of proteinase-activated receptor-4 inhibits the eosinophil recruitment induced by eotaxin- 1 in the pleural cavity of mice. Pharmacology. doi:10.1159/000319751.

20. Gomides, L.F., I.D. Duarte, R.G. Ferreira, A.C. Perez, J.N. Francischi, and A. Klein. 2012. Proteinase-activated receptor-4 plays a major role in the recruitment of neutrophils induced by trypsin or carrageenan during pleurisy in mice. Pharmacology. doi:10.1159/000337378.

21. Asokananthan, N., P.T. Graham, J. Fink, D.A. Knight, A.J. Bakker, A.S. McWilliam, et al. 2002. Activation of protease-activated receptor (PAR)-1, PAR-2, and PAR-4 stimulates IL-6, IL-8, and prostaglandin $\mathrm{E} 2$ release from human respiratory epithelial cells. $J$ Immunol 168: 3577-3585.

22. Steinhoff, M., J. Buddenkotte, V. Shpacovitch, A. Rattenholl, C. Moormann, N. Vergnolle, et al. 2005. Proteinase-activated receptors: transducers of proteinase-mediated signaling in inflammation and immune response. Endocr Rev 26: 1-43.

23. Macfarlane, S.R., M.J. Seatter, T. Kanke, G.D. Hunter, and R. Plevin. 2001. Proteinase-activated receptors. Pharmacol Rev 53: 245-282.

24. Adams, M.N., R. Ramachandran, M.K. Yau, J.Y. Suen, D.P. Fairlie, M.D. Hollenberg, and J.D. Hooper. 2011. Structure, function and pathophysiology of protease activated receptors. Pharmacol Ther 130: 248-282.

25. Bolton, S.J., C.A. McNulty, R.J. Thomas, C.R.A. Hewitt, and A.J. Wardlaw. 2003. Expression of and functional responses to protease-activated receptors on human eosinophils. J Leukoc Biol 74: 60-68.

26. Schmidlin, F., S. Amadesi, K. Dabbagh, D.E. Lewis, P. Knott, N.W. Bunnett, et al. 2002. Protease-activated receptor 2 mediates eosinophil infiltration and hyperreactivity in allergic inflammation of the airway. J Immunol 169: 5315-5321.

27. Klein, A., A. Talvani, P.M. Silva, M.A. Martins, T.N. Wells, A. Proudfoot, et al. 2001. Stem cell factor-induced leukotriene B4 production cooperates with eotaxin to mediate the recruitment of eosinophils during allergic pleurisy in mice. J Immunol 167: 524531.

28. Ramachandran, R., and M.D. Hollenberg. 2008. Proteinases and signalling: pathophysiological and therapeutic implications via PARs and more. Br J Pharmacol 153(Suppl 1): S263-S282.

29. Molino, M., E.S. Barnathan, R. Numerof, J. Clark, M. Dreyer, A. Cumashi, et al. 1997. Interactions of mast cell tryptase with thrombin receptors and PAR-2. J Biol Chem 272: 4043-4049.

30. Reed, C.E., and H. Kita. 2004. The role of protease activation of inflammation in allergic respiratory diseases. $J$ Allergy Clin Immunol 114: 997-1008.

31. Vliagoftis, H., P. Lacy, B. Luy, D. Adamko, M. Hollenberg, D. Befus, and R. Moqbel. 2004. Mast cell tryptase activates peripheral blood eosinophils to release granule-associated enzymes. Int Arch Allergy Immunol 135: 196-204.

32. Krishna, M.T., A. Chauhan, L. Little, K. Sampson, R. Hawksworth, T. Mant, et al. 2001. Inhibition of mast cell tryptase by inhaled APC 366 attenuates allergen induced late-phase airway obstruction in asthma. J Allergy Clin Immunol 107: 1039-1045.

33. Su, X., E. Camerer, J.R. Hamilton, S.R. Coughlin, and M.A. Matthay. 2005. Protease-activated receptor-2 activation induces acute lung inflammation by neuropeptide-dependent mechanisms. $J$ Immunol 175: 2598-2605.

34. Vergnolle, N. 1999. Proteinase-activated receptor-2-activating peptides induce leukocyte rolling, adhesion, and extravasation in vivo. Jimmunol. 163: 5064-5069.

35. Miike, S., A.S. McWilliam, and H. Kita. 2001. Trypsin induces activation and inflammatory mediator release from human eosinophils through protease-activated receptor-2. J Immunol 167: 6615-6622.

36. Senden, N.H., T.M. Jeunhomme, J.W. Heemskerk, R. Wagenvoord, C. van't Veer, H.C. Hemker, and W.A. Buurman. 1998. Factor Xa induces cytokine production and expression of adhesion molecules by human umbilical vein endothelial cells. J Immunol 161: 43184324.

37. De Campo, B.A., and P.J. Henry. 2005. Stimulation of proteaseactivated receptor-2 inhibits airway eosinophilia, hyperresponsiveness and bronchoconstriction in a murine model of allergic inflammation. Br J Pharmacol 144: 1100-1108.

38. Stenton, G.R., O. Nohara, R.E. Déry, H. Vliagoftis, M. Gilchrist, A. Johri, et al. 2002. Proteinase-activated receptor (PAR)-1 and -2 agonists induce mediator release from mast cells by pathways distinct from PAR-1 and PAR-2. J Pharmacol Exp Ther 302: 466-474.

39. Lohman, R.J., A.J. Cotterell, G.D. Barry, L. Liu, J.Y. Suen, D.A. Vesey, and D.P. Fairlie. 2012. An antagonist of human protease activated receptor-2 attenuates PAR2 signaling, macrophage activation, mast cell degranulation, and collagen-induced arthritis in rats. FASEB J. doi:10.1096/fj.11-201004.

40. Dinh, Q.T., A. Cryer, M. Trevisani, S. Dinh, S. Wu, L.B. Cifuentes, et al. 2006. Gene and protein expression of proteaseactivated receptor 2 in structural and inflammatory cells in the nasal mucosa in seasonal allergic rhinitis. Clin Exp Allergy 36: 1039-1048. 